\title{
Modelagem Matemática: uma proposta de ensino para alunos deficientes visuais
}

Resumo: Apresentamos os resultados de uma proposta pedagógica embasada na Modelagem Matemática como estratégia de ensino, na inclusão de um aluno com deficiência visual, no contexto da Educação Tecnológica, bem como abordamos suas contribuições para os processos de ensino e de aprendizagem. A pesquisa, de natureza qualitativa, é do tipo estudo de caso. Os resultados analisados apontam que a Modelagem Matemática utilizada como estratégia de ensino da Matemática: a) oferece maior autonomia e inclusão dos alunos deficientes visuais; b) possibilita o reexame de conhecimentos matemáticos e sua aplicação em situações-problema, partindo de situações do cotidiano; c) permite a geração de Modelos Matemáticos mentais e não mentais.

Palavras-chave: Modelagem Matemática. Ensino. Deficiência Visual.

\section{Mathematical Modelling: a teaching proposal for visually impaired students}

Abstract: We present the results of a pedagogical proposal based on Mathematical Modeling as a teaching strategy, in the inclusion of a visually impaired student, in the context of Education Technological, as well as addressing their contributions to the teaching and learning processes. The approach was designed for a visual impaired student based on Mathematical Modeling as main teaching strategy. The qualitative reasearch was conducted through a study of case. The results points that the Mathematical Modeling used as a teaching strategy of Mathematics learning: a) provides greater autonomy and inclusion of visually impaired students; b) empowers the re-examination of mathematical knowledge and its application in daily problem situations; c) allows the creation of mental and non-mental Mathematical Models.

Keywords: Mathematical Modeling. Teaching. Visual Impairment.

\section{Modelización Matemática: una propuesta didáctica para estudiantes con discapacidad visual}

Resumen: Presentamos los resultados de una propuesta pedagógica basada en el Modelado Matemático como estrategia de enseñanza, en la inclusión de un estudiante con discapacidad visual, en el contexto de la Educación Tecnológica, así como nos acercamos 
sus aportes a los procesos de enseñanza y aprendizaje. La investigación, de carácter cualitativo, es del tipo estudio de caso. Los resultados analizados muestran que el Modelado Matemático utilizado como estrategia de enseñanza para las Matemáticas: a) ofrece mayor autonomía e inclusión de estudiantes con discapacidad visual; b) permite reexaminar el conocimiento matemático y su aplicación en situaciones problemáticas, a partir de situaciones cotidianas; c) permite la generación de Modelos Matemáticos mentales y no mentales.

Palabras clave: Modelización Matemática. Enseñanza. Discapacidad Visual.

\section{Introdução}

O ensino de Matemática vem sendo discutido há muitos anos e ainda carece de ponderações e estudos. Trata-se de um tema que não se circunscreve apenas em termos de transferência e/ou transposição de conhecimentos e informações ao aluno, mas com tentativas de explorar distintos métodos e estratégias de ensino. Assim, ensinar Matemática, almejando a diversificação das estratégias, possibilita ao aluno uma melhor compreensão se a compararmos às ocasiões em que o desenvolvimento das tarefas ocorre apenas com o uso de livros didáticos, resolução de listas de exercícios, fórmulas matemáticas de caráter linear, repetidas pelos estudantes sem uma relação com situaçõesproblema do cotidiano. Ademais, é possível aperfeiçoar o aprendizado, despertando no aluno maior interesse pelo que é trabalhado nas aulas de Matemática.

Em efeito, entendemos que, ao nos referirmos à educação inclusiva, a abordagem do ensino da Matemática não pode ser diferente. Assim, ponderamos que deliberar sobre essa temática, é uma atividade que impõe desafios, seja pela delicadeza do tema, ou pela ausência de ampla e/ou massiva divulgação, mas que é imperiosa, visto que vem eivando as deliberações do tecido social mais inclinado ao tema nos vários nichos que o integram.

Sendo assim, em consideração à defesa da educação inclusiva, conjecturamos que deliberar e/ou refletir sobre tão relevante temática exige que compreendamos o caminho a ser trilhado na perspectiva de quais atuações devem ser efetivadas para a inclusão de todos. Nessa expectativa, a intenção é que as diretrizes da educação inclusiva não sejam utilizadas apenas como meio de apagar focos de combustão (MANTOAN, 2015).

Ante essa reflexão, somos provocados a examinar a educação inclusiva, fitando seus fundamentos teóricos, seu arcabouço de leis e sua trajetória na história, com a intenção de vislumbrar suas conquistas em todos os campos do conhecimento que 
integram o ambiente educacional. Assim, o ensino de Matemática requer alterações, haja vista ser considerado, no senso comum, difícil demais para ser compreendido. A esse respeito, Silva e Klüber (2012) salientam que essa dificuldade é responsável pela pouca compreensão da Matemática que os alunos possuem, o que, em nossa concepção, está relacionada com as estratégias de ensino utilizadas nessa área do conhecimento. Dessa forma, é relevante observar que a conjectura enfatizada pelos autores fez com que nos debruçássemos sobre o uso da Modelagem Matemática como estratégia de ensino, buscando abordar a inclusão de deficientes visuais.

Com a proposta pedagógica desenvolvida, procuramos contribuir para a inclusão de um aluno com deficiência visual (cego) na Educação Profissional, abordando o cálculo da área de superfície de utensílios domésticos. Assim, este estudo tem por objetivo relatar as contribuições da Modelagem Matemática como estratégia de ensino na inclusão de estudantes deficientes visuais, no âmbito da Educação Tecnológica, em um Instituto Federal de Educação, Ciências e Tecnologia.

A proposta pedagógica ocorreu em cinco etapas, distribuídas em onze encontros, dos quais dezessete horas foram dedicadas a um aluno deficiente visual (cego), integrante de uma turma do curso de Tecnologia em Sistemas para Internet - TSI, de um Instituto Federal de Educação, Ciências e Tecnologia. A atividade, desenvolvida por um aluno deficiente visual, em parceria com um colega, agraciou os tópicos conceituais sobre grandezas e medidas, pois, segundo a concepção de Burak (2004), a Modelagem Matemática tem seu processo desenvolvido de forma compartilhada.

Para o cálculo da área de superfície, usaram-se utensílios domésticos, preparados e adaptados à temática abordada. É oportuno salientar que este texto dirige seu olhar, com maior proeminência, aos modelos matemáticos resultantes da proposta pedagógica.

\section{Inclusão de deficientes visuais}

Neste momento, é oportuno salientar que as deliberações acerca das pessoas deficientes nunca se furtaram dos meios sociais, não pela relevância de sua integração ou por respeito, mas pelas diferenças e/ou características proeminentes que esses indivíduos apresentavam. Sobre isso, Jannuzzi (2004) conjectura que a sociedade, por conveniências, admitia que esses sujeitos fossem excluídos da esfera social. Esse comportamento ocorria 
em consequência da ignorância humana, que tratava os pertencentes ao citado grupo como seres indignos de vida (FERNANDES, 2013). Porém, o surgimento do espírito científico, após a Idade Média, aflorou uma nova maneira de ver o homem, e o tecido social passou a encarar problemas que há muito tempo eram tratados de forma superficial (SILVA, 1987). Tal fato se deu em consequência da disseminação do conhecimento e do desenvolvimento da humanidade (FERNANDES, 2013).

Assim, naturalmente, as deliberações acerca da inclusão de deficientes se estenderam ao ambiente escolar, chegando aos dias atuais com força e logrando avanços. $\mathrm{Na}$ atualidade, já é natural falar abertamente da necessidade de se buscarem meios de ampliar o acesso dos deficientes à educação formal e fortalecer a sua permanência no ambiente escolar, possibilitando-lhes lograr emancipação. Para ilustrar a concepção anterior, podemos citar iniciativas sociais de atendimento especializado, como: Associação de Assistência à Criança Deficiente (AACD), fundada em 1950; Instituto Santa Terezinha, fundado em 1929; Instituto Educacional São Paulo (IESP), fundado em 1954; Associação de Pais e Amigos de Excepcionais do Rio de Janeiro (APAE), fundado em 1954, entre outros.

Além disso, podemos mencionar as políticas públicas que visam assegurar o direito do deficiente à educação e eliminar aspectos negativos, pois sabemos que ela, a educação, tem sido marcada pelo fracasso e evasão de uma parte significativa dos seus alunos, que são marginalizados pelo insucesso e constantes privações, resultantes da exclusão escolar e da social (MANTOAN, 2015). Esses são ingredientes que vêm fazendo com que a educação inclusiva busque superar seus entraves e se consolide.

A esse respeito, Ziliotto (2015, p. 13) concebe que, "atualmente, vivemos um novo paradigma [...], que impulsiona os sistemas de ensino a repensarem seu fazer pedagógico para proporcionar educação inclusiva de qualidade a todos os alunos - entre eles os alunos público-alvo da educação especial”. Assim, tanto os sistemas de ensino quanto o professor, este considerado o elemento chave do ensino, são impelidos a buscarem alternativas com o intuito de propor e efetivar ações que fortaleçam a inclusão. Estas podem ser distribuídas no currículo, nas avaliações, nas metodologias e/ou nas estratégias de ensino (GLAT e FERNANDES, 2005). Ademais, levam as instituições de ensino a proverem aberturas a serem percorridas pelos alunos deficientes visuais, concedendo-lhes 
a autonomia, bem como a oportunidade de mostrarem que apenas são desprovidos de capacidade visual.

Nesse cenário, entendemos que a Modelagem Matemática se apresenta como um potencial a ser empregado como estratégia de ensino para alunos deficientes visuais. Ela carrega em seu bojo a possibilidade de tornar as aulas de Matemática mais concretas e aprazíveis ao estudante, provocando a participação em equipe no desenvolvimento das atividades (ALMEIDA, SILVA e VENTURAN, 2013). No entanto, são necessárias mudanças, tanto na postura do professor no que tange a um caráter mais voltado à mediação, quanto à do aluno, no que concerne à inclinação para a sua independência, fortalecendo, consequentemente, a inclusão.

\section{Modelagem Matemática}

A presença de um aluno com deficiência visual em uma sala de aula regular, $a$ priori, pode causar perplexidade e/ou estranheza a quem não acompanha e/ou desconhece o processo de aprendizagem desse grupo, que conserva todas as demais faculdades mentais, estando, portanto, hábil ao aprendizado como os demais que integram as salas de aula regulares. Dessa forma, os sistemas de ensino são responsavelmente convidados a estruturarem o ensino de tal modo que eles - os alunos deficientes visuais - possam, de fato, sentirem-se inclusos e participar de todas as atividades propostas.

Nessa expectativa, a Modelagem Matemática se apresenta como estratégia de ensino de Matemática aos estudantes deficientes visuais, levando-os a perceber a aprendizagem como algo mais relacionado às situações do dia a dia, bem como a criar relações entre a teoria Matemática e a prática desenvolvida a partir de situações vivenciadas. Afinal, qual a melhor e mais adequada forma de ensinar senão aquela que busca criar possibilidades de ensino a partir de experiências que viabilizem profundas marcas de aprendizado mediante o resultado de práticas que os alunos podem experimentar?

Ante essas exposições, Burak (2004) salienta que a Modelagem Matemática envolve uma estratégia integral, haja vista ela englobar o interesse e a obstinação do aluno, perpassando pela reestruturação da conduta do professor e colocá-lo como mediador. Segundo o autor, nessa metodologia, o ensino e a pesquisa são inseparáveis, 
proporcionando, ainda, a interação entre os alunos. Ademais, o mencionado pesquisador enfatiza que, na Modelagem, o discente encontra sentido no que é estudado em sala de aula em consequência de seus interesses serem atendidos e da concretização de suas objetividades. Dessa forma, evita que o aluno desanime, fazendo com que ele se dedique a construir seu conhecimento e assuma posturas afirmativas em relação à Matemática.

Diante dessas ponderações, cabe esclarecer que a proposta pedagógica desenvolvida se assentou nas concepções de Biembengut e Hein (2019), que propõem a Modelagem Matemática como uma estratégia favorável ao ensino da Matemática, em que o professor tem a possibilidade de escolher o tema ou conceder a decisão aos alunos. Ainda segundo de Barbosa (2001), a Modelagem Matemática é um espaço de aprendizagem no qual os alunos são levados a investigar, por meio da Matemática, situações de outras áreas do cotidiano, sem estabelecimento de procedimentos previamente prefixados.

Assim, o emprego da Modelagem Matemática como estratégia de ensino oportuniza ultrapassar, paulatinamente, a trivialidade e a forma segmentada que atualmente norteia, em grande parte, o ensino, haja vista que se empenha em beneficiar o interesse dos alunos, favorecendo uma educação mais significativa. Dessa forma, quebra correntes ideológicas, como as de que a Matemática se retroalimenta e se basta em si mesma, além de ser uma disciplina mais abstrata, sem vinculação com os problemas do cotidiano de todo e qualquer aluno. Nesse sentido, Conceição e Moreira (2015) sustentam que, por longo tempo, a Matemática foi questionada sobre sua utilidade, aplicação e a necessidade de estudá-la.

No entanto, mesmo com esses questionamentos, a Matemática ainda ostenta o posto proeminente nas atividades que o homem desenvolve, considerando que ela passou a ser estruturada a partir da necessidade de o indivíduo organizar seu conhecimento. Com efeito, não poderia ser diferente no ambiente escolar, no qual lhe é conferida uma posição de destaque. Sobre isso, Conceição e Moreira (2015) salientam que é a oportunidade de se repensarem formas de ensino para levar o aluno a perceber as diversas relações da teoria matemática com a vida cotidiana. É nessa teia que relatamos a prática de ensino desenvolvida com um aluno deficiente visual (cego) que, a partir de agora, visando a uma melhor compreensão e acompanhamento, denominamo-lo A1, e seu colega que com ele 
participou da prática, A23.

\section{Caracterização da turma e metodologia}

A instituição de ensino em que a proposta pedagógica foi desenvolvida é um Instituto Federal de Educação, Ciências e Tecnologia, localizado na Região Sul do Brasil, frequentado por alunos dos cursos técnicos, tecnólogos, bacharelados e licenciaturas nos turnos diurno e noturno. As aulas da proposta pedagógica aconteceram nos meses de setembro, outubro e novembro de 2017 e foram encerradas no dia 29 de novembro do mesmo ano.

Conforme já salientado, a turma na qual foi desenvolvida a proposta pedagógica cursava Tecnologia em Sistemas para Internet - TSI e era composta de vinte e dois estudantes. Cumpre informar que era a única em que havia aluno deficiente visual (AI), motivo pelo qual a escolhemos.

Entre os vinte e dois alunos, estava A23, dezoito anos, sem problemas visuais, que participou da assistência ao aluno A1 durante a proposta pedagógica. Cabe salientar que ambos eram integrantes do curso superior de Tecnologia em Desenvolvimento de Sistemas para Internet, matriculados no turno vespertino. Também é importante enfatizar que este artigo se limita a fitar somente os modelos matemáticos obtidos pelo aluno A1 e seu par (A23).

A pesquisa teve abordagem qualitativa, na perspectiva de Lakatos e Marconi (2001), que a julgam adequada para entender e descrever com exatidão os símbolos e concepções contidas no contexto investigado. Essa ideia é corroborada por Triviños (1995), quando sustenta ser tal abordagem a melhor forma de analisar o que não é possível quantificar. A pesquisa ocorreu por meio de estudo de caso e com base na concepção de Gil (2008), que enfatiza que esse tipo de estudo oportuniza conhecer e compreender as características da população envolvida.

Para a coleta de dados, foram utilizadas entrevistas semiestruturadas, observações simples, gravações de áudios, fotografias e diário de campo visando à melhor aproximação possível da compreensão do problema norteador da pesquisa e de seu possível resultado. A proposta metodológica foi baseada no cálculo de área de superfície 
externa de utensílios domésticos. Cabe salientar que o estudo foi desenvolvido a partir da assinatura do Termo de Consentimento Livre e Esclarecido dos sujeitos participantes, além de obter a autorização do Instituto por meio da assinatura da carta de anuência.

\section{Análise dos resultados da atividade}

A análise dos resultados centrou-se na perspectiva textual discursiva baseada em Moraes e Galiazzi (2013), que concebem a construção de categorias de análise visando agrupar as informações e respostas conforme suas características. Assim, a categoria dos modelos matemáticos surgiu de uma questão que integrou a proposta pedagógica e na qual também é possível observar o processo de interação entre os alunos A1 e A23. Na referida questão, perguntou-se a ambos qual seria o valor da superfície externa superior do utensílio conforme a Figura 1.

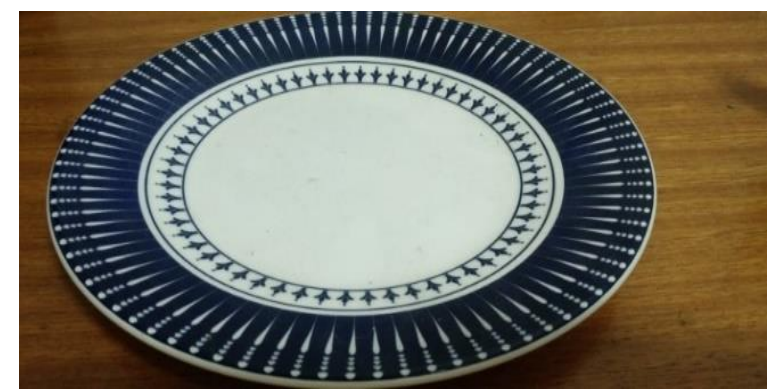

Figura 1: Utensílio doméstico (prato) usado durante a atividade de Modelagem Matemática (Acervo da Pesquisa)

O diálogo entre os alunos A1 e A23, retirado de uma das categorias que compõem a análise dos resultados da dissertação, intitulada Inclusão de alunos deficientes visuais no ensino de Matemática no contexto da Educação Tecnológica em um Instituto Federal de Educação, Ciências e Tecnologia, explana a resolução da mencionada questão:

A1: Pode usar alguma coisa pra medir, tipo uma régua? [para descobrir o valor da superficie externa de uma figura geométrica].

Pq (nomenclatura designada para identificação do pesquisador): Sim. Você acha que seria adequada uma régua?

A1: É que uma régua não daria 100\%, porque tem uma profundidade.

Esclarecemos que o aluno A1, nesse momento, mostrou-se preocupado com a exatidão aferida do utensílio, como é possível fitar na sua prolação abaixo. No ínterim da atividade, o aluno A23 questionou: 
A23: A gente teria que medir quadrado ou a gente teria que medir... [o aluno A23 expressa dúvida, hesitação] medir cúbico?

A1: A área total do prato, né?

$P q$ : Não, apenas a área da superfície superior.

A1: Tá, como ela tem uma profundidade uma régua não seria o ideal, né?

$P q$ : O que seria o ideal?

A1: Tem uma fita métrica?

A23: É dificil! [aluno A23 considerou dificil e/ou pouco provável ter à disposição uma fita métrica naquele instante].

Explicitamos que, no início, ficou decidido que não seria disponibilizado material aos alunos para auxiliá-los na efetivação da atividade. Essa diretriz teve por objetivo leválos a se inquietarem, pesquisar e/ou buscar meios de solucionar o que lhes fora proposto. Essa inquietação se evidenciou na interpelação do aluno A1.

\section{A1: Tem uma fita métrica?}

Pq: Pronto, aqui tem uma fita métrica, você (Al) pode tocar.

Salientamos que preparamos essa fita pensando que o aluno deficiente visual a solicitaria. Para produzi-la, fizemos uma adaptação, colocando cola de relevo (hipoalérgica) sobre a fita métrica para representar a medida em centímetros de um ponto a outro como está indicado na Figura 2.

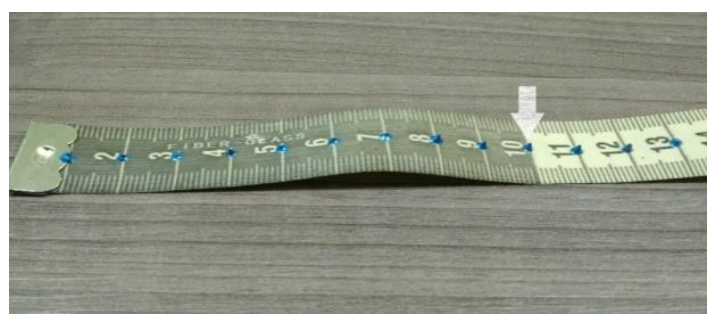

Figura 2: Fita métrica com adaptação em alto-relevo com destaque para marcação que indica os centímetros (Acervo da Pesquisa)

A23: Al quer medir?

A1: Começa aí.

É perceptível, no recorte acima, que, na prolação entre os alunos A1 e A23, o primeiro evidencia certa hesitação, quiçá por temor de enveredar em dubiedades na aferição do valor da superfície do utensílio. Porém, o segundo insiste: 
A23: Vai você.

A1: Tá. [o aluno Al concorda de forma vigorosa].

A23: Tem que ser pela pontinha, já começa a contar pela ponta [aluno A2 guiando o aluno A1 para usar a fita métrica].

A1: Deu $19 \mathrm{~cm}$. - Tá certinho?

A23: Deu $19 \mathrm{~cm}$ !

Constata-se que A1, mesmo contando com a assistência de A23 e manipulando a fita métrica adaptada à sua deficiência visual, duvidou quando aferiu o diâmetro da superfície do utensílio:

\section{A1: Ah isso é diâmetro, né?}

Entretanto, evidenciamos que, nessa hesitação, não há ausência de conhecimento teórico matemático, mas apenas uma carência de convicção no resultado obtido. Nesse instante, o professor que mediou a prática com os demais grupos de alunos, aqui identificado como P2, questionou o pesquisador ao solicitar confirmação se os alunos poderiam requerer "coisas". Elucidamos que essa expressão se refere a instrumentos de medidas e/ou outros meios que colaborassem na resolução da atividade. Na continuidade, os alunos A1 e A23 seguiram deliberando sobre as informações que surgiram conforme expressam os excertos que seguem:

A23: A medida da superficie seria... [dúvida sobre a regra a ser empregada no cálculo da área do círculo]. Seria... É que eu esqueci a regra [o aluno mostra confusão sobre qual instrumento teórico matemático usar para solução do problema]. Pesquisar no google a fórmula do cálculo de superficie?

A1: Vamos

O diálogo estabelecido entre os alunos A1 e A23 contribuiu, substancialmente, para que ambos encontrassem e/ou rememorassem o conhecimento teórico matemático que os auxiliou na resolução da questão proposta no que se refere ao uso de uma ferramenta tecnológica (smartphone) para pesquisar informações favoráveis às suas necessidades. Isso implica, essencialmente, segundo Biembengut (2009), conduzir o alunos dos mais variados níveis de ensino a lançar mão da pesquisa sobre assuntos de sua predileção. Essa atitude o leva a desenvolver a criatividade no desenrolar da solução dos problemas, fortalecendo sua criticidade no exame dos resultados (BASSANEZI, 2006). 
Perante essas concepções, é fácil observar que a Modelagem Matemática traz como peculiaridade a pesquisa, o que motiva o aluno a obliterar sua passividade, alcançando ares de proatividade e não apenas esperar que o conhecimento seja oferecido pelo professor. Burak e Klüber (2013) corroboram essa concepção ao sustentarem que a Modelagem Matemática oportuniza ao aluno a adoção de um caráter de investigação à medida que ele é levado a granjear, optar e estruturar as informações obtidas. O surgimento desse caráter passa a adjetivar a conduta do discente não somente no seu percurso estudantil, mas em toda sua vida.

Nessa concepção, os autores reforçam que a Modelagem Matemática pode favorecer a investigação, fato observado quando os alunos envolvidos na atividade encontraram a expressão $A=\pi \mathrm{r}^{2}$ via internet, que permitiu calcular a área do círculo. Esse foi, inicialmente, o modelo matemático encontrado/aplicado por A1 e A23. Convém esclarecer que as grandezas físicas que constituem essa expressão são: A — área do círculo (superfície do utensílio); $\mathrm{r}$ - raio do círculo e $\pi(\mathrm{Pi})=3,14$ (constante) usada para o cálculo da área do círculo.

Mesmo não sendo um modelo inédito, vemos uma aplicação de um modelo matemático por meio de uma expressão que procurou traduzir a situação-problema proposta (BIEMBENGUT e HEIN, 2019). Assim, não se causou prejuízo ou desvirtuamento ao desenvolvimento da proposta pedagógica, pois o foco não era gerar e/ou encontrar um modelo matemático inédito. Entendemos e corroboramos que não existe rigidez na resolução de problemas matemáticos, os caminhos são diversos e não conduzem a uma única solução (BUENO, ALENCAR e MILLONES, 2017). Entendemos que o relevante é o processo decorrido para chegar à uma situação de adoção de decisões e/ou compreensão do objeto estudado com o uso da Matemática (BARBOSA, CALDEIRA e ARAÚJO, 2007). Na Figura 3, consta a escrita dos alunos A1 e A 23.

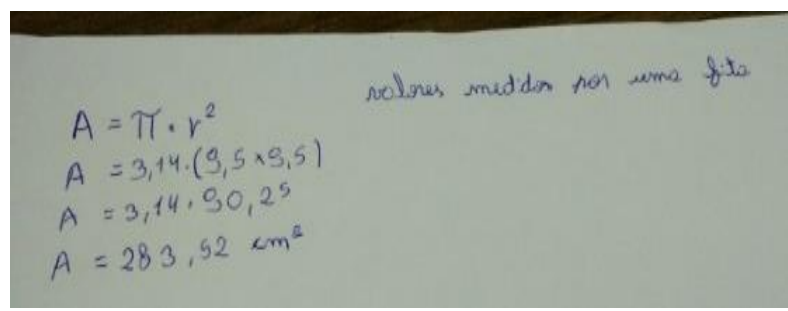

Figura 3: Notação Matemática para o cálculo de área do círculo feita pelos alunos A1 e A23 (Acervo da Pesquisa)

Nesse seguimento, transcrevemos um diálogo estabelecido entre os alunos A1 e 
A23:

A1: $A=\pi r^{2}$ ?

A23: $\operatorname{Sim}, A=\pi r^{2}$.

A1: Tá, o raio é a metade do diâmetro. Então...

A23: 19 [diâmetro]... Dá menos que dez.

A1: Aham... É 9,5 cm. Ah é! [expressão de satisfação em descobrir o valor].

A23: Agora 9,5 $x$ 9,5.

A1: Vezes não.

A23: É ao quadrado.

A1: Ah é, tá certo!

Num primeiro momento e sob um olhar pouco cuidadoso, é possível que o diálogo seja considerado conflituoso, o que, em parte, é verdade. Mas, numa análise mais atenta, essa prolação dos alunos A1 e A23 - em torno da estruturação, sedimentação e recomposição de conhecimentos teóricos matemáticos — possibilitou que ambos defendessem seus conhecimentos prévios:

A23: Multiplicado [referindo-se ao valor encontrado de $(9,5)^{2}$ por 3,14 , valor de $\pi$ ] dá 283,52 $\mathrm{cm}^{2}$. Tu concorda comigo? [resultado encontrado carece de mais lapidação]. Eu peguei e dividi o valor do comprimento [referindo-se ao diâmetro] para dar o raio que deu $9,5 \mathrm{~cm}$.

Neste momento, é importante relembrar que o trabalho teve um caráter colaborativo entre os dois alunos. Assim, quando A23, que fazia uso de uma calculadora no smartphone, perguntou ao A1 se ele endossava o resultado obtido, este fez uma pausa e, mostrando abissal concentração ao fazer o cálculo mentalmente, proferiu: "É 283,38 $\mathrm{cm}^{2}$ ". Esclarecemos que, nesse ponto da pesquisa, mesmo considerando relevante um possível exame sobre a cognição que fez parte do cálculo que emergiu, não buscamos compreender como se deu o processo cognitivo presente na resolução do problema proposto por A1, já que fugiria dos objetivos que guiaram a pesquisa que deu origem a este artigo.

Diante disso, com facilidade, percebe-se que o resultado prolatado destoa do valor calculado com o auxílio da calculadora. Em efeito, emergiu uma dissimilitude de 0,14 $\mathrm{cm}^{2}$ não levada em consideração, já que que essa atividade não buscava valores absolutos, 
mas sim examinar como o aluno A1, com deficiência visual, poderia representar os modelos matemáticos que satisfizessem a proposta pedagógica de Modelagem Matemática.

Mesmo assim é imperioso considerar a cognição do aluno A1, que expôs o resultado 283,38 como solução da questão, anteriormente mencionado, sendo relevante respeitar a cronologia do surgimento dos resultados que se mostraram imbricados. Dessa forma, expomos a resposta ao questionamento feito ao aluno A1 a fim de saber como ele calculou (mentalmente), gerando $283,38 \mathrm{~cm}^{2}$ :

A1: Ah não sei se sei explicar bem direitinho... [aluno aparentemente se mostra um pouco inseguro em expor o cálculo que fizera]. Mas eu primeiro fiz a multiplicação do nove por nove (parte inteira) do raio (do utensílio usado na proposta pedagógica) que o A23 me ajudou a encontrar. Depois eu multipliquei o valor depois da virgula (valor decimal que constitui o valor do raio) por nove. Só que esse eu multipliquei duas vezes. Eu fiz também a multiplicação da parte da vírgula por ela mesma.

É relevante elucidar que o aluno A1 expôs o trajeto pelo qual efetivou o cálculo. Entretanto, ele não mostrou, tampouco verbalizou especificamente, a terminologia da colocação dos valores que integram o cálculo, pois, como é possível observar na prolação, referiu-se aos valores pelo nome dos algarismos ou posição antes ou após a vírgula, o que, a priori, não causou entraves. O nomeado estudante completou que "Aí, depois que eu fiz a multiplicação eu somei (adição) toda essa parte”.

Essas últimas considerações, em particular quando A1 salienta que "Ah não sei se sei explicar bem direitinho...; Aí, depois que eu fiz a multiplicação eu somei (adição)", evidenciam que, diante da nova situação que lhe fora proposta, ele buscou obter subsídios no procedimento cognitivo. Segundo Moreira (2014), faz-se necessária a construção de um modelo de trabalho mental, que pode implicar um modelo matemático, dando forma à solução do problema proposto. Ainda para o autor, modelos matemáticos científicos, certificados por professores e cientistas, são trabalhados pelo aluno por meio de modelos mentais (JOHSON-LAIRD, 2013), dando espaço, posteriormente, à reconstrução de modelos matemáticos científicos.

Dessa forma, para materialização e melhor compreensão dos trabalhos efetivados pelo aluno A1, descrevem-se as multiplicações, respeitando a organização por ele 
salientada, a saber: $9 \times 9=81 ; 9 \times 0,5=4,5 ; 9 \times 0,5=4,5 ; 0,5 \times 0,5=0,25$; $81+4,5+4,5+0,25=90,25$. Nessa representação, são possíveis outras organizações numéricas; entretanto, a intenção foi somente expor o detalhamento que A1 fez no decurso para o cálculo.

Em sua prolação, A1, expondo o cálculo efetivado, esclarece que:

A1: Quando eu somei (adição) essa parte, ai eu peguei e multipliquei pelo valor do 3,14 ( $\pi$ ). Nessa parte, eu usei a multiplicação do noventa por três (parte inteira de $\pi$ ); depois eu multipliquei o noventa pelo valor depois da vírgula (valor decimal de $\pi$ ) e, também, multipliquei o três pela parte da vírgula (referência à parte decimal resultante do raio ao quadrado) e a última parte multipliquei as vírgulas [ao usar o termo "vírgulas", ele se refere aos valores decimais de $\pi$ e da multiplicação oriunda do valor decimal do raio ao quadrado]. Depois disso, eu somei (adição) tudo (valores resultantes das multiplicações).

Para clarificar esses produtos, expressamo-los a seguir: $90 \times 3=270$; $90 \times 0,14=12,6 ; 3 \times 0,25=0,75 ; 0,14 \times 0,25=0,035$. É oportuno elucidar que a adição desses resultados totaliza 283,385 (conferidos). Porém, ao examinarmos a verbalização do aluno A1 quando salienta 283,38 como resultado, não encontramos indícios sobre a desconsideração da terceira ordem decimal que compõe o resultado, que, a nosso ver, não prejudicou o resultado. Assim, aproveitamos a oportunidade para elucidar que os pormenores feitos por A1 sobre o desenvolvimento do cálculo mental aqui exposto, foi efetivado, sequencialmente, à exposição da notação $A=\pi \mathrm{r}^{2}$ e empregada na resolução da proposta pedagógica, podendo ser acompanhada sua construção no diálogo que segue:

A1: Isto? [expressão de dúvida]

A23: 9,5 eu multipliquei por 9,5 isso é o quadrado.

A1: É! Se a área da superficie é $\pi r^{2}$ então tá certo. [o aluno A1 não se mostrava ainda plenamente à vontade com o resultado encontrado, expressando dúvida].

A23: E depois eu multipliquei 9,5 × 9,5 deu 90,25. Ai peguei 90,25 e multipliquei por $3,14[\pi]$ que deu $283,52 \mathrm{~cm}^{2}$.

A1: Tá! Pode ser isso mesmo. [Não demonstrou confiança no que foi encontrado].

A23: Eu olhei no Google para ver se nossa fórmula estava certa. Área é igual $\pi r^{2}$.

A1: É isso mesmo. Tá então será... [exprimindo ainda dúvida sobre o resultado encontrado].

A23: Então são 283,38 $\mathrm{cm}^{2}$. [Passou a adotar o resultado que o aluno A1 
encontrou].

Diante desse recorte, inferimos que o desconforto do aluno A1, percebido tanto por nós quanto pelo aluno A23 e em destaque nas alocuções acima, surtiu efeito no direcionamento do resultado da atividade. Dito de outra forma, conduziu o aluno A23 a desprezar o resultado oferecido por ele e a adotar o mais exato do seu colega. É oportuno proferir que o papel do professor nas atividades de Modelagem Matemática é portar-se como mediador (MALHEIROS, 2005), ideia corroborada por Burak e Aragão (2012), que afirmam ser imprescindível o docente assumir essa postura.

Assim, encontrado o valor de $283,38 \mathrm{~cm}^{2}$, o pesquisador questionou o aluno A1 se, para realizar a atividade proposta, seria conveniente que o utensílio que ele tinha em mãos sofresse adaptações. "Como assim? Adaptado como?", exclamou, mostrando surpresa e curiosidade.

Eivado pelo papel de mediador, que se fez mais necessário nesse momento, o pesquisador pediu ao aluno A1 que tocasse novamente o utensílio para ter a real noção do que fora questionado, ou seja, qual seria o valor da área da superfície (área do círculo) do utensílio. Essa condução, entendemos que "orientar é indicar caminhos, é fazer perguntas, é não aceitar o que não é bom, é sugerir procedimentos [...] é não dar respostas prontas e acabadas [...] não é esperar que o aluno simplesmente siga exemplos" (ALMEIDA, SILVA e VERTUAN 2013, p. 24).

Diante da indagação, o aluno A1 prosseguiu:

A1: Sim, claro [respondeu com firmeza e prosseguiu no toque do utensílio].

Pq: Como você descreveria a superficie dele?

A1: É lisa.

Pq: Não tem indicação de nenhuma medida. Se tivesse medidas nele, seria mais viável para vocêfazer a atividade?

A1: Tipo... [dúvida sobre o que seriam as medidas no utensílio].

A23: Tipo se tivesse uma textura que nem uma parede, mas que representasse medidas.

A1: Sei lá. [Dúvida e aparente receio pelo desconhecido].

A intervenção junto ao aluno A1 teve como foco apresentar outra maneira possível de desenvolver a atividade. Porém, como mostra o diálogo acima, ela (a intervenção oral) 
foi insuficiente para elucidar e retirar as incertezas que A1 tinha acerca das adaptações do utensílio com uma textura que descrevia as medidas da superfície do utensílio. Assim, para eliminar a dúvida, substitui-se o utensílio não adaptado pelo adaptado (Figuras 4 e $5)$.

Pq: Vou trocar [substituição do utensílio normal pelo utensílio com a adaptação].

A1: Tá bem [Aluno A1 demonstra expectativa].

$P q$ : Um utensílio da mesma forma. Só que tem uma textura. Cada espaço desses [quadradinhos] representa $1 \mathrm{~cm}^{2}$.

A1: Hum! Ah, sim! [aluno demonstrou admiração e curiosidade ao tocar o utensílio]. Tá, mas ai a gente teria que contar de um por um? [aparente indisposição, partindo do pressuposto de que faria, individualmente, a contagem de cada espaço].

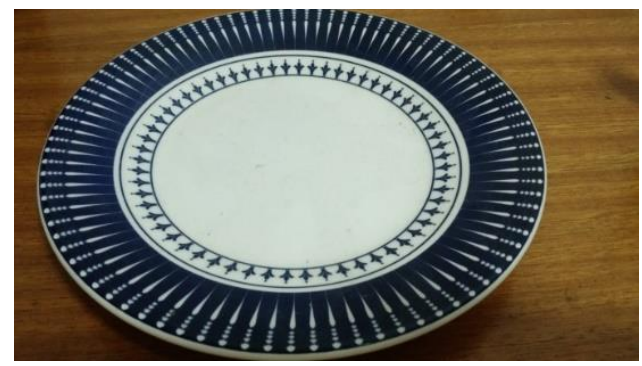

Figura 4: Utensílio doméstico usado na proposta pedagógica de Modelagem Matemática sem adaptação (Acervo da Pesquisa)

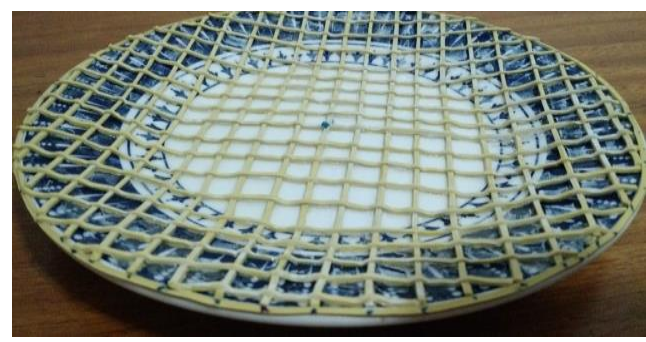

Figura 5: Utensílio doméstico usado na proposta pedagógica de Modelagem Matemática com adaptação em alto-relevo (Acervo da Pesquisa)

Pq: Não sei. Procure ver todas as informações que constam no utensílio adaptado.

Nesse instante, o aluno A1 mostrou-se absorto em buscar elementos que possivelmente pudessem estar no utensílio. Entretanto, persistiu:

A1: Chegar em 200... [risos]. Vamos conferir A23?

A23: Podemos tentar. 
A1: [Risos de desaprovação e desânimo].

A23: Tu Al conta a metade e eu conto o resto. Pode ser?

A1: Será que a gente consegue? [hesitação]!

A princípio, o aluno A1 não mostrou interesse pela adaptação feita no utensílio. Ademais, pareceu-nos que ele influenciou A23 a segui-lo, já que os dois pretendiam conferir, em particular, cada reprodução de $\mathrm{cm}^{2}$ da adaptação, que delineou o valor da superfície do utensílio, como é possível verificar na deliberação transcrita acima entre ambos. Sobre essas observações, ponderamos que a experiência do aluno A1 na busca de percursos para satisfazer a resolução do problema proposto se mostrou, nesse momento, elementar, uma vez que indicou apenas a somatória dos espaços que delineavam os centímetros quadrados que integravam a superfície do utensílio, cujo ipsis verbis pode ser representado por $A=\{1,2,3,4 \ldots\}$, o que propicia ficar a par da área global da superfície do utensílio. No entanto, é imperioso chamar a atenção que, nesse percurso, a linguagem empregada em sua composição é o que determina o modelo matemático (TORTOLA, 2012).

Contudo, a sugestão do emprego da linguagem simplificada não é pretexto para admoestação ao modelo matemático que ela possa descrever e/ou representar, mas sim, ensejo. Conforme a concepção de Sassaki (1977), o desenvolvimento da autonomia oportuniza a composição reflexiva com o emprego de diretivas adequadas a serem empregadas nas múltiplas circunstâncias encontradas no cotidiano. Esse ponto de vista é reforçado por Burak e Aragão (2012) ao declararem que os alunos deverão incumbir-se de decisões, criar autonomia e serem responsáveis quando envoltos em atividades de Modelagem Matemática.

Diante dessas concepções, convém considerar que poderia não ter emergido um modelo matemático sofisticado e fulgente que respondesse ao que foi requerido na proposta pedagógica de Modelagem Matemática, ou que satisfizesse os críticos matemáticos mais argutos dessa vertente por mero voluntarismo acadêmico. Mesmo assim, foi um momento ímpar de intrepidez, que, por meio da Modelagem Matemática, conferiu ao aluno A1 espaço para agir como construtor dos seus conhecimentos, evoluir sua competência de apreciar e colaborar para sua autonomia (VERONEZ, 2009).

Pq: Você usou a fórmula do cálculo de área do círculo? 
A1: É, sim.

Pq: Você soube o valor do raio?

A1: Sim.

Pq: De posse desse valor, fez a aplicação na fórmula?

A1: Aham [sim].

Pq: Você precisou saber só o raio?

A1: Então teria que achar bem o meio.

A1: Seria esse aqui bem o meio? [aluno toca o ponto adaptado e encontra a marcação do meio do diâmetro do utensílio em alto-relevo — Figura 6].

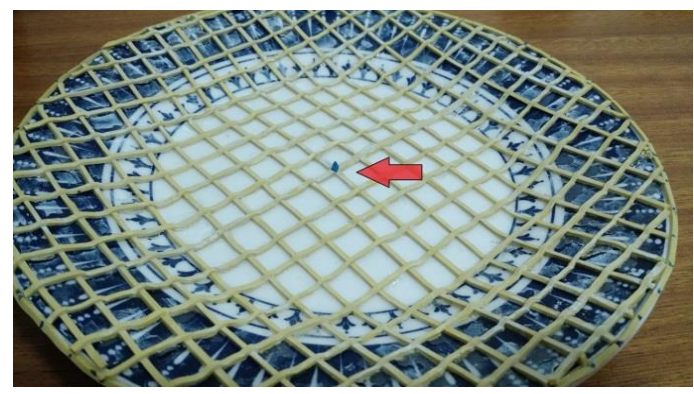

Figura 6: Utensílio doméstico adaptado em alto-relevo com destaque para adaptação que indica a medida do raio (Acervo da Pesquisa)

Pq: Pronto.

A pouca experiência do aluno A1 e a originalidade da atividade proposta tornaram imperiosa a necessidade de insuflar o papel de mediador do pesquisador na atividade de Modelagem Matemática, dada a necessidade de suscitar sua atenção aos pormenores e informações que compunham o utensílio. Assim, procuramos lhes conceder a oportunidade de granjear informações que possibilitassem "a obtenção [...] de Modelos Matemáticos” (BASSANEZI, 2006, p. 24).

Transcorrida essa mediação, os alunos A1 e A23 retomaram a atividade:

A1: Vamos contar pra cá [direção do centro para a borda do utensílio]. 1, 2, 3... Deu nove. E... [reconhecendo a adaptação que descreve meio $\mathrm{cm}^{2}$ na borda do utensílio como mostra a Figura 7]. 


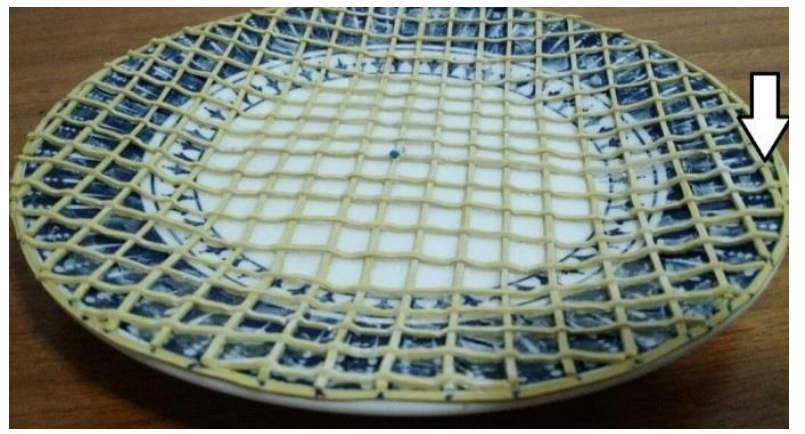

Figura 7: Utensílio doméstico adaptado em alto-relevo com destaque para a representação de meio $\mathrm{cm}$ na borda do utensílio (Acervo da Pesquisa)

A23: - Ali onde tu contaste nove tem um pedacinho.

A1: É né! [admiração]. Que pedacinho sobra? [o aluno demonstra surpresa e admiração no reconhecimento da textura do utensílio].

A23: Sim.

A1: Exato. Deu nove pra cada lado. É um pedacinho que sobrou.

A23: Que é o meio que a gente contou.

A1: Exato. Então tá certinho.

A23: E agora tu vai contar pros lados? [aluno A2 dirigindo-se ao aluno A1 e questionando se contaria a partir do meio do diâmetro para os lados através do raio].

A1: Não tem necessidade, dá a mesma coisa.

A23: Eu acho que sim. É que tem que dá a mesma coisa [valor].

A1: Tá. 1, 2, 3... O bem do meio. No caso ficaria o bem do meio aqui. [Aluno A1 mostrando ao aluno A23 o meio do utensílio adaptado]. Dá nove para cada lado.

No diálogo, evidencia-se uma maior convicção na postura do aluno A1 perante as informações que adquiriu ao tocar o utensílio. Ele mostrou certa resistência, mesmo que tênue, em acordar com o aluno A23 a possibilidade de fazer a contagem dos espaços que delineavam o raio de utensílio. Entretanto, sem embargos, aceitou a opinião do seu colega ao realizar o cômputo dos espaços do diâmetro e não apenas o do raio. É possível fitar também, nessa deliberação, o trabalho solidário entre ambos, apresentando a “manipulação de informações" (GÖRGEN e ZIEGLER, 2014, p. 209). Transcorrido esse ponto da atividade, conforme foi possível acompanhar no diálogo anterior, A1 mostrou nova perspectiva sobre a atividade que lhe fora proposta conforme expressa o colóquio a seguir:

Pq: Dessa forma achou melhor? 
A1: Assim, eu conseguiria eu fazer a conta, sozinho, saber fazer a conta. [Aluno A1 dá ênfase nessa expressão]. Senão, para que eu pudesse medir, o A23 teria que me ajudar um pouco para ler o resultado que deu né? [O aluno expressa um pouco de dúvida]. E assim, com essas divisões [adaptações da superfície do utensílio] eu conseguiria fazer a conta sozinho.

Perante essas alocuções, é pertinente observar que o aluno A1 logrou maior autonomia no transcorrer da atividade, visto que enfatizou não ser necessário o auxílio do colega, dada a adaptação feita no utensílio empregado na atividade de Modelagem Matemática. Isso robustece a cooperação que essa vertente pode oferecer no aumento da independência.

Ademais, é oportuno elucidar que, durante a atividade de Modelagem Matemática, o aluno A1 não enfrentou dificuldades em relação aos conhecimentos matemáticos que pudessem tolher a resolução nela requerida como podemos observar na alocução sobre o questionamento a ele realizado pelo aluno A23 acerca de sua concordância com a solução a priori encontrada. Com essa inquirição, A1 se lançou ao cálculo municiado de informações que lhe eram conhecidas, apresentando um resultado um pouco diferente do primeiro, com leve variação, como já anunciado anteriormente.

Essa observação nos leva a reiterar que a pesquisa que resultou neste artigo não se propôs a buscar comparativos sobre os valores encontrados pelos alunos A1 e A23. É imperioso destacar esse ponto, pois foi possível observar que os modelos matemáticos encontrados fizeram sentido, sem empecilhos, e que se atendeu à problemática proposta nessa atividade. Em efeito, foi uma oportunidade de mostrar modelos matemáticos factíveis, que poderão ter seu emprego em vários cenários análogos ao modelado (BASSANEZI, 2006).

Ainda há que se observar que devemos fugir de modismos no ambiente educacional e cuidar para que os modelos matemáticos oriundos da modelação não se tornem desprezíveis conforme observação de Barbosa (2001). Segundo esse autor, a Modelagem não deve ser fitada como fim, mas sim um meio de refletir a realidade vivenciada. Posto isso, reforçamos que ela, a Modelagem Matemática, contribui para a estratégia de ensino, sendo um meio, um caminho possível de ser trilhado no ensino de Matemática. 


\section{Considerações finais}

A partir do desenvolvimento da proposta pedagógica, abordando o tema Contribuições da Modelagem Matemática como estratégia de ensino na inclusão de alunos deficientes visuais no âmbito da Educação Tecnológica, é possível inferir que o uso da Modelagem pode colaborar com o ensino da Matemática para alunos com deficiência visual (cegos). Nessa perspectiva, o uso dessa vertente ainda pode conferir segurança e autonomia aos alunos deficientes visuais nas aulas de Matemática, conforme testemunhado na proposta pedagógica, oportunizando, também, a obtenção de modelos matemáticos que satisfaçam a inquirição da atividade. De fato, o aluno deficiente visual foi levado a colocar em prática seus conhecimentos teóricos matemáticos, bem como refletir e questionar a validade dos resultados emergidos.

Vale ressaltar que utilizar distintas estratégias de ensino da Matemática pode contribuir para a motivação, participação e independência do aluno deficiente visual. Nesse sentido, as possibilidades ofertadas pela Modelagem Matemática o forçam a perceber que a disciplina em questão oferece formas versáteis na solução de problemas do cotidiano.

Urge também que as aulas de Matemática não tenham um invólucro embasado apenas na resolução de listas de exercícios, elaboradas, não raro, formalmente, sem trazer relação com problemas que os estudantes vivem e presenciam. Tal fato não ocorre com o uso da Modelagem Matemática, pois "o aluno vê sentido naquilo que estuda, em função [...] de seus interesses, da realização dos seus objetivos, não haverá desinteresse, pois trabalha com entusiasmo e perseverança [o que possibilita] [...] atitudes positivas em relação à Matemática" (BURAK, 2004, p. 10).

Neste sentido, o professor de Matemática é convidado a se reinventar, colocandose como mediador no desenrolar das aulas de Matemática, evitando dar "respostas prontas e acabadas" (ALMEIDA, SILVA e VERTUAN, 2013, p. 24). Possibilita-se, assim, como já proferido, que o aluno fortaleça sua autonomia e independência, e o professor não seja uma fonte exclusiva de conhecimento, mas um colaborador ativo, que gerencia o processo de ensino, no qual tanto ele como os discentes estejam envolvidos com o uso da Modelagem Matemática.

Abordadas essas considerações, chamamos a atenção para a utilização da 
Modelagem Matemática, que proporcionou a geração de modelos matemáticos capaz de fazer com que os alunos A1 e A23 processassem informações e as comunicassem. Nessa seara, podemos salientar o modelo $A=\pi \mathrm{r}^{2}$, cujo emprego foi satisfatório e válido. Podemos ainda observar que, na construção da resposta exigida pela atividade, houve bom relacionamento entre os participantes (alunos A1 e A23), oportunizando a deliberação e compartilhamento dos resultados.

Ademais, constatamos que o modelo mental que o aluno A1 utilizou na resolução da proposta pedagógica partiu de um processo cognitivo interno (ARZARELLO, PEZZI e ROBUTT, 2007). Este culminou em um modelo matemático descrito por meio do uso da linguagem matemática, que mostrou sua aplicabilidade, as grandezas envolvidas e a validade dos resultados encontrados como foi possível acompanhar anteriormente.

Posto isso, encerramos estas considerações na expectativa de que contribuímos para avigorar o entusiasmo dos que defendem e estudam a Modelagem Matemática como estratégia de ensino, bem como proporcionar um ambiente mais inclinado à pesquisa, à independência intelectual e ao empenho na participação das aulas significativas. Sendo assim, evidenciou-se que é possível utilizar a Modelagem Matemática em situações homeomorfas, considerando as devidas adaptações quando necessárias.

\section{Referências}

ALMEIDA, Lourdes Werle; SILVA, Karina Patrícia; VENTUAN, Rodolfo Eduardo. Modelagem Matemática na educação básica. São Paulo: Contexto, 2013.

ARZARELLO, Ferdinando; PEZZI, Giovanni; ROBUTT, Ornella. Modelling body motion: an approach to functions using measure instruments. In: BLUM, Werner; GALBRAITH, Peter L.; HENN, Hans-Wolfgang. Modelling and applications in Mathematics Education. Springer: New York, 2007, p. 129-136.

BARBOSA, Jonei Cerqueira; CALDEIRA, Ademir Donizeti; ARAÚJO, Jussara de Loila. (Org.). Modelagem Matemática na Educação Matemática brasileira: pesquisas e práticas educacionais. Recife: SBEM, 2007.

BARBOSA, Jonei Cerqueira. Modelagem na Educação Matemática: contribuições para o debate teórico. In: $24^{\mathrm{a}}$ REUNIÃO ANUAL DA ANPED, 2001, Caxambu. Anais da $24^{\mathrm{a}}$ ANPED. Santos: ANPED, 2001, p. 1-15.

BASSANEZI, Rodney Carlos. Ensino-aprendizagem com modelagem matemática. 3. ed. São Paulo: Contexto, 2006. 
BIEMBENGUT, Maria Salett. 30 Anos de Modelagem Matemática na Educação Brasileira: das propostas primeiras às propostas atuais. Alexandria, Florianópolis, v. 2, n. 2, p. 7-32, jul. 2009.

BIEMBENGUT, Maria Salett.; HEIN, Nelson. Modelagem Matemática no ensino. São Paulo: Contexto, 2019.

BURAK, Dionísio. Modelagem Matemática e a sala de aula. In: I ENCONTRO PARANAENSE DE MODELAGEM EM EDUCAÇÃO MATEMÁTICA, 2004, Londrina. Anais do I EPREM. Londrina: UEL, 2004, p. 1-10.

BUENO, Simone; ALENCAR, Edvonete Souza de; MILLONES. Teresa Sofia Oviedo. Reflexões e desafios da resolução de problemas nas aulas de Matemática: um ensaio teórico. Educação Matemática Debate, Montes Claro, v. 1, n. 1, p. 9-27, jan./abr. 2017.

BURAK, Dionísio; ARAGÃO, Rosália Maria Ribeiro. A modelagem matemática e relações com a aprendizagem significativa. Curitiba: CRV, 2012.

BURAK, Dionísio; KLÜBER, Tiago Emanuel. Educação Matemática: contribuições para a compreensão da sua natureza. Acta Scientiae, Canoas, v. 10, n. 2, p. 93-106, jul./dez. 2013.

CONCEIÇÃO, Eliseu de Jesus da.; MOREIRA, Francis Miller Barbosa. A Modelagem Matemática no ensino da Matemática: uma aplicação no cultivo da alface. In: ENCONTRO MINEIRO DE EDUCAÇÃO MATEMÁTICA, 7, 2015, Juiz de Fora. Anais do VII EMEM: Práticas educativas e de pesquisa em Educação Matemática. Juiz de Fora: UFJF/SBEM-MG, 2015, p. 1-11.

FERNANDES, Sueli de Fátima. Fundamentos para educação especial. Curitiba: InterSaberes, 2013.

GIL, Antonio Carlos. Métodos e técnicas de pesquisa social. 6. ed. São Paulo: Atlas, 2008.

GLAT, Rosana; FERNANDES, Edicléia Mascarenhas. Da Educação Segregada à Educação Inclusiva: uma breve reflexão sobre os paradigmas educacionais no contexto da Educação Especial brasileira. Revista Inclusão, Brasília, v. 1, n. 1, p. 35-39, out. 2005.

GÖRGEN, Maria Cristina; ZIEGLER, Janaina de Ramos. In: MUNHOZ, Angélica Vier; GIONGO, Ieda Maria. (Org.). Observatório da Educação I: tendências no ensino de Matemática. Porto Alegre: Evangraf, 2014, p. 208-217.

JANNUZZI, Gilberta Sampaio de Martino. A educação do deficiente no Brasil: dos primórdios ao início do século XXI. Campinas. Autores Associados, 2004.

JOHSON-LAIRD, Philip. Mental models. Cambridge: Harvard University Press, 2013.

LAKATOS, Eva Maria; MARCONI, Mariana de Andrade. Fundamentos de metodologia científica. 4. ed. São Paulo. Atlas, 2001. 
MALHEIROS, Ana Paula. Produção matemática dos alunos em um ambiente de modelagem. 2005. 180f. Dissertação (Mestrado em Educação Matemática) — Instituto de Geociências e Ciências Exatas. Universidade Estadual Paulista. Rio Claro.

MANTOAN, Maria Teresa Engler. Inclusão escolar: O que é? Por quê? Como fazer?. 7. ed. São Paulo:. Summus Editorial, 2015.

MORAES, Roque; GALIAZZI, Maria do Carmo. Análise textual discursiva. 2. ed. rev. Ijuí: Unijuí, 2013.

MOREIRA, Marcos Antonio. Modelos científicos, modelos mentais, modelagem computacional e modelagem matemática: aspectos epistemológicos e implicações para o ensino. Revista Brasileira de Ensino de Ciência e Tecnologia, Curitiba, v. 7, n. 2, p. 120, maio/ago. 2014.

SASSAKI, Romeu Kazumi. Inclusão: construindo uma sociedade para todos. 3. ed. Rio de Janeiro: WVA, 1997.

SILVA, Otto Marques. A epopeia ignorada: a pessoa deficiente na história do mundo de ontem e de hoje. São Paulo: Cedas, 1987.

SILVA, Vantielen da Silva.; KLÜBER, Tiago Emanuel. Modelagem Matemática nos Anos Iniciais do Ensino Fundamental: uma investigação imperativa. Reveduc, São Carlos, v. 6, n. 2, p. 228-249, nov. 2012.

TORTOLA, Emerson. Os usos da linguagem em atividades de Modelagem Matemática nos anos iniciais do Ensino Fundamental. 2012. 168f. Dissertação (Mestrado em Ensino de Ciências e Educação Matemática) - Centro de Ciências Exatas. Universidade Estadual de Londrina. Londrina.

TRIVIÑOS, Augusto Nibaldo Silva. Introdução à pesquisa em Ciências Sociais: a pesquisa qualitativa em Educação. São Paulo: Atlas, 1995.

VERONEZ, Michele Regiane Dias. Modelagem Matemática como alternativa pedagógica na educação básica. ENCONTRO PARANAENSE DE EDUCAÇÃO MATEMÁTICA, 10, 2009, Guarapuava. Anais do X EPREM. Guarapuava: SBEM-PR, 2009.

ZILIOTTO, Gisele Sotta. Educação especial na perspectiva inclusiva: fundamentos psicológicos e biológicos. Curitiba: Inetrsaberes, 2015. 